\title{
RELAÇÕES DE BROMÉLIAS EPIFÍTICAS COM CARACTERÍSTICAS DOS FORÓFITOS EM DIFERENTES ESTÁDIOS SUCESSIONAIS DA FLORESTA OMBRÓFILA DENSA, SANTA CATARINA, BRASIL
}

\author{
Annete Bonnet*, Maike Hering de Queiroz†, Osmir José Lavoranti** \\ *Bióloga, Dra ., Pós-Doutoranda em Eng. Florestal, UFPR - a bonnet@hotmail.com \\ **Estatístico, Dr., Embrapa Florestas - osmir@cnpf.embrapa.br \\ Recebido para publicação: 05/09/2006 - Aceito para publicação: 31/10/2006
}

\begin{abstract}
Resumo
O presente estudo teve o objetivo de caracterizar a ocorrência de bromélias epifíticas em quatro estádios sucessionais (capoeirinha, capoeira, capoeirão e floresta secundária) da Floresta Ombrófila Densa em encostas da Ilha de Santa Catarina, Santa Catarina, Brasil. As bromélias foram classificadas em grupos de ocorrência ampla e restrita de acordo com a amplitude de sua distribuição. Os forófitos foram selecionados através do método de pontos quadrantes, e suas características foram analisadas em associação com o número de espécies de bromélias, através da análise multivariada. Foram registradas cinco espécies de bromélias na capoeira, oito no capoeirão e onze na floresta secundária. A similaridade foi maior entre o capoeirão e a floresta secundária, com trocas e substituições de espécies e gêneros nos sucessivos estádios de regeneração da floresta. As bromélias apresentaram correlações diretas com a altura total dos forófitos, indicando que o tempo é um fator importante na colonização de bromélias epifíticas.

Palavras-chave: Bromélias epifíticas; Floresta Ombrófila Densa; forófitos; sucessão.
\end{abstract}

\begin{abstract}
Relationship of epiphytic bromeliads with phorophytes at different stages of secondary succession of Atlantic Rainforest. The present study was carried out aiming to characterize the occurrence of epiphytic bromeliads at four sucessional stages (capoeirinha, capoeira, capoeirão and secondary forest) of Atlantic Rainforest slopes, in Santa Catarina Island, Santa Catarina, Brasil. The bromeliads were classified in groups of restricted and wide occurrence based on the extent of distribution. The phorophytes were selected by the point -quadrant method and their attributes analyzed as variables in association with bromeliads species number through multivariate analyses. Five bromeliad species were found in capoeira, eight in capoeirão and eleven in secondary forest. The floristic similarity was higher between capoeirão and secondary forest, with species and genera changes and substitutions in the successive stages of forest regeneration. The bromeliads presented direct correlations with phorophytes total height, indicating that the time is a important factor in epiphytic bromeliads colonization.

Keywords: Atlantic Rainforest; epiphytic bromeliads; phorophytes; succession.
\end{abstract}

\section{INTRODUÇÃO}

Nas florestas tropicais, as epífitas são elementos importantes na composição de espécies (GENTRY; DODSON, 1987a; LUGO; SCATENA, 1992). Participam dos mecanismos de ciclagem de nutrientes (NADKARNI, 1984) e também disponibilizam água, abrigo, alimentação e sítio de reprodução para outros organismos, principalmente da fauna, caracterizando-se como ampliadoras da biodiversidade local (ROCHA et al., 2004).

No Brasil, Bromeliaceae é amplamente distribuída, destacando-se em levantamentos de epífitas em várias formações vegetais, como na Floresta Ombrófila Mista do Paraná (DITTRICH et al., 1999; KERSTEN; SILVA, 2002), na Floresta Ombrófila Densa do Rio Grande do Sul (BREIER, 1999; 
WAECHTER, 1992), do Paraná (GATTI, 2000; KERSTEN; SILVA, 2001), do Rio de Janeiro (FONTOURA et al., 1997) e na Floresta Estacional do Rio Grande do Sul (AGUIAR et al., 1981; ROGALSKI; ZANIN, 2003) e de São Paulo (DISLICH; MANTOVANI, 1998; PINTO et al., 1995).

A distribuição e sucesso das bromélias na colonização dos forófitos devem-se, principalmente, à capacidade de obtenção de nutrientes e umidade diretamente da atmosfera ou das cisternas formadas pelo imbricamento da base das suas folhas, tornando-as, dessa maneira, estreitamente relacionadas e dependentes do clima de cada região (LUGO; SCATENA, 1992), respondendo com diferenças na composição e abundância às diferentes florestas e aos ambientes que as compõem (GENTRY; DODSON, 1987a; NIEDER et al., 2000; BONNET, 2006).

Estudos sobre a dinâmica de colonização das bromélias nos estágios sucessionais da Floresta Ombrófila Densa são escassos. Alguns desses estudos mostraram a variação das espécies em diferentes ambientes de uma mesma região (FISCHER; ARAÚJO, 1995; ROGALSKI, 2002; BONNET, 2006; BONNET et al., 2006) e em áreas com diferentes níveis de intervenção antrópica (ALMEIDA et al., 1998; HOELTGEBAUM, 2003; BONNET; QUEIROZ, 2006).

A composição e a distribuição das espécies de bromélias são influenciadas pelas características dos forófitos, através da sua arquitetura, altura, diâmetro, textura, estabilidade e porosidade do ritidoma, toxinas presentes e húmus acumulado (GENTRY; DODSON, 1987b; GARCIA-FRANCO; RICOGRAY, 1988; FONTOURA et al., 1997; NIEDER et al., 2000). No entanto, quando se considera a família Bromeliaceae no Brasil, poucos autores mediram essas variáveis em campo e analisaram suas relações. Assim, o presente estudo teve como objetivo caracterizar a ocorrência de bromélias epifíticas em diferentes estádios sucessionais da Floresta Ombrófila Densa, relacionando-a com as características dos forófitos.

\section{MATERIAL E MÉTODOS}

\section{Área de estudo}

O estudo foi desenvolvido nos anos de 1999 e 2000, na porção norte da Ilha de Santa Catarina ( $27^{\circ} 31^{\prime} \mathrm{S}$ e $\left.48^{\circ} 30^{\prime} \mathrm{W}\right)$, na cidade de Florianópolis, estado de Santa Catarina. O clima é do tipo Cfa (mesotérmico úmido, com verões quentes e chuvas distribuídas durante o ano), com temperatura média anual de $21,15^{\circ} \mathrm{C}$, média mensal para os meses de verão de $23,46^{\circ} \mathrm{C}$ e para os meses de inverno de 16,75 ${ }^{\circ} \mathrm{C}$. A umidade é alta, em torno de $80 \%$, com pluviosidade anual de $1.527 \mathrm{~mm}$, bem distribuída durante todo o ano, não existindo estação seca ou chuvosa (PORTO FILHO, 1993). A forma de relevo mais comum é montanhoso, com amplitudes altimétricas superiores a $300 \mathrm{~m}$ e vertentes com diferentes graus de inclinação, sendo predominantes os Cambissolos e os Neossolos Litólicos. O substrato geológico é composto por granitóides submetidos à tectônica rúptil relacionada ao mecanismo de "rifteamento" do Atlântico Sul, evidenciado pela abundância de sulcos e vales estruturais profundos (IPUF, 1997).

Para o estudo das bromélias, foram escolhidos quatro ambientes em encosta, característicos da Floresta Ombrófila Densa, em diferentes estádios de regeneração (KLEIN, 1980), sendo três localizados dentro da Unidade de Conservação Ambiental Desterro (UCAD) e apenas o estádio capoeira localizado na área de entorno da Unidade: i) capoeirinha - área em $270 \mathrm{~m}$ de altitude, com vegetação caracterizada pela associação Tibouchino-Dodonaeetum viscosae (QUEIROZ, 1994), onde Dodonaea viscosa Jacq. (Sapindaceae) e Tibouchina urvilleana (DC.) Cogn. (Melastomataceae) podem atingir até 2,5 m de altura. Essas associações são densas e homogêneas, com poáceas e asteráceas compondo o estrato herbáceo; ii) capoeira - área em 15 m de altitude, com associação Guapiro-Miconietum ligustroides (QUEIROZ, 1994) que possui Miconia ligustroides Naud. (Melastomataceae), com até $5 \mathrm{~m}$ de altura, como espécie dominante. É acompanhada pelas espécies Guapira opposita (Vell.) Reitz (Nyctaginaceae), que marca fisionomicamente a associação, e por Roupala cataractarum Sleumer (Proteaceae), Myrsine coriacea (Sw.) R. Br. (Myrsinaceae), Ilex dumosa Reissek e I. theezans Mart. (Aquifoliaceae); iii) capoeirão - área em $240 \mathrm{~m}$ de altitude, onde a associação Miconietum cinnamomifoliae (QUEIROZ, 1994) é dominada fisionomicamente por Miconia cinnamomifolia Naud. (Melastomataceae), sendo acompanhada principalmente por Hyeronima alchorneoides Allemão (Euphorbiaceae), Piptocarpha tomentosa Baker (Asteraceae), Cecropia glaziovi Snethlage (Moraceae), Cabralea canjerana (Vell.) Mart. (Meliaceae), Trema micrantha (L.) Blume (Ulmaceae), Casearia sylvestris Sw. (Flacourtiaceae); iv) floresta secundária - área em $235 \mathrm{~m}$ de altitude, onde podem ser destacadas as seguintes espécies: Alchornea 
triplinervia (Spreng.) Müll. Arg. (Euphorbiaceae), Guapira opposita, Rollinia sericea (R. E. Fr.) R. E. Fr. e Guatteria australis A. St.-Hil. (Annonaceae), além de Cyathea schanschin Mart. (Cyatheaceae), Talauma ovata A. St.-Hil. (Magnoliaceae) e Bathysa meridionalis L. B. Sm. e Downs (Rubiaceae) (KLEIN, 1980).

\section{Procedimento metodológico}

Cada forófito foi considerado uma unidade amostral, definida pelo método dos pontos quadrantes (MUELLER-DOMBOIS; ELLENBERG, 1974), através de transectos com 15 pontos separados $10 \mathrm{~m}$ entre si, totalizando 60 forófitos por ambiente estudado (WAECHTER, 1992). O critério para inclusão do forófito foi o diâmetro à altura do solo (DAS) $\geq 2 \mathrm{~cm}$ na capoeirinha; diâmetro à altura do peito $(\mathrm{DAP}) \geq 5 \mathrm{~cm}$ na capoeira e $\mathrm{DAP} \geq 10 \mathrm{~cm}$ no capoeirão e floresta secundária. Foram registradas as alturas totais e de inversão morfológica (PIM), que representa o início da copa, de cada forófito. A variável exuberância de copa foi utilizada para registrar a integridade e o aspecto geral da copa dos forófitos, sendo consideradas aquelas com todas as ramificações e folhas vigorosas (copa exuberante), as copas com algumas ramificações secas (copa média) e as copas precárias, com indícios de senilidade ou com danos causados pela queda de outras árvores (copa fraca). O ritidoma de cada espécie de forófito foi caracterizado quanto à textura, sendo denominado de liso, áspero ou rugoso, e quanto à sua estabilidade, podendo ser considerado persistente ou descamante (WAECHTER, 1992). Em cada unidade amostral, foram registradas as espécies de bromélias presentes, assim como a presença ou ausência de plântulas.

Analisou-se a diversidade de Bromeliaceae, em cada área estudada, através do índice de Shannon (H'), do Índice de Pielou (E), que se refere à eqüidade, e do Índice de Jaccard (IJ), que se refere à similaridade florística (MAGURRAN, 1988). As espécies de bromélias registradas foram enquadradas em grupos de ocorrência (restrita e ampla).

As espécies de bromélias férteis encontradas nas áreas de estudo foram herborizadas e incluídas no Herbário do Departamento de Botânica da Universidade Federal de Santa Catarina (FLOR). As bromélias estéreis e não identificadas no campo foram levadas para cultivo ou observadas in situ até a floração. Os nomes das espécies foram verificados no Index Kewensis (1997). Para registro e identificação das bromélias e plântulas, quando necessário, utilizou-se binóculo $(7$ x 35) e técnicas de arvorismo.

Para avaliar a relação das características dos forófitos (exuberância de copa, estabilidade e textura do ritidoma, DAP, altura total e PIM) com o número de espécies de bromélias registradas nos diferentes estádios sucessionais, utilizou-se a matriz de correlação bisserial por ponto (KRAEMER, 1982) e de Pearson (DRAPER; SMITH, 1981). Após verificar os efeitos da multicolinearidade, procederam-se as análises de componentes principais e fatorial em cada estádio sucessional. Na seqüência, as variáveis com baixa comunalidade (inferior a 0,7 ) foram eliminadas, sendo suas correlações rotacionadas, por eixo principal, pelo procedimento varimax (JOHNSON; WICHERN, 1998). Os fatores que explicaram, conjuntamente, mais de $70 \%$ da variância total e apresentaram autovalores superiores a 1 (KAISER 1958) foram retidos para análise gráfica, sendo os dois primeiros fatores, retentores de praticamente todo padrão de variação, relacionados em gráficos biplot (GABRIEL, 2002).

\section{RESULTADOS}

Foi determinado um total de 14 espécies de bromélias epifíticas pertencentes a cinco gêneros e duas subfamílias em três estádios sucessionais, onde também houve registro de plântulas (Tabela 1). Um exemplar encontrado na floresta secundária não foi identificado no nível específico.

O gênero com maior número de espécies no estádio de capoeira foi Tillandsia, com três espécies. No estádio capoeirão, Tillandsia e Vriesea ocorreram com quatro espécies cada, e na floresta secundária, Vriesea apresentou cinco espécies e Tillandsia quatro. Nos três estádios, espécies do gênero Tillandsia foram as mais freqüentes, como já publicado em Bonnet e Queiroz (2006).

$\mathrm{Na}$ capoeira, capoeirão e floresta secundária houve aumento no número de espécies e nos índices de diversidade, aumento esse que acompanhou a progressão dos estádios sucessionais. A eqüidade igualase entre o capoeirão e a floresta secundária (Tabela 1).

Apenas duas espécies de bromélias foram registradas nos três estádios sucessionais: Tillandsia geminiflora Brongn. e Tillandsia stricta Sol. ex Sims, as quais formaram o grupo de ocorrência ampla B 
(Tabela 1). No capoeirão e na floresta secundária ocorreu um grupo de espécies categorizado como de ocorrência ampla A que, juntamente com o grupo anterior, justifica a maior similaridade entre esses estádios $(\mathrm{IJ}=0,73)$. Em razão das espécies de ocorrência restrita (grupo de ocorrência restrita A e B), a similaridade foi muito mais baixa entre os estádios capoeira e floresta secundária $(\mathrm{IJ}=0,14)$. Do mesmo modo, devido ao baixo número de espécies comuns entre a capoeira e o capoeirão, sua similaridade também foi muito baixa $(\mathrm{IJ}=0,18)$.

Tabela 1. Espécies de bromélias epifíticas registradas em três estádios sucessionais e seus grupos de ocorrência, Ilha de Santa Catarina.

Table 1. Epiphytic bromeliad species registered in three sucessional stages and theirs occurrences groups, Santa Catarina Island.

\begin{tabular}{|c|c|c|c|c|c|}
\hline \multirow[b]{2}{*}{ Espécies } & \multirow[b]{2}{*}{ Subfamília } & \multicolumn{3}{|c|}{ Estádios sucessionais } & \multirow{2}{*}{$\begin{array}{l}\text { Grupos de } \\
\text { ocorrência }\end{array}$} \\
\hline & & Capoeira & Capoeirão & $\begin{array}{c}\text { Floresta } \\
\text { secundária }\end{array}$ & \\
\hline Aechmea lindenii (E. Morren) Baker & Bromelioideae & & & & \\
\hline Billbergia zebrina (Herb.) Lindl. & Bromelioideae & & & & restritas A \\
\hline Tillandsia mallemontii Glaz. ex Mez & Tillandsioideae & & & & \\
\hline Aechmea nudicaulis (L.) Grieseb. & Bromelioideae & & & & \\
\hline Nidularium innocentii Lem. & Bromelioideae & & & & restritas B \\
\hline Vriesea $\mathrm{sp}$. & Tillandsioideae & & & & \\
\hline Tillandsia tenuifolia $\mathrm{L}$. & Tillandsioideae & & & & \\
\hline Vriesea flammea L.B. Sm. & Tillandsioideae & & & & \\
\hline Tillandsia usneoides (L.) L. & Tillandsioideae & & & & amplas A \\
\hline Vriesea incurvata Gaud. & Tillandsioideae & & & & ampias A \\
\hline Vriesea philippocoburgii Wawra & Tillandsioideae & & & & \\
\hline Vriesea vagans (L.B. Sm.) L.B. Sm. & Tillandsioideae & & & & \\
\hline Tillandsia geminiflora Brongn. & Tillandsioideae & & & & amplas B \\
\hline Tillandsia stricta Sol. ex Sims & Tillandsioideae & & & & ampras D \\
\hline Índice de Shannon (H') & & 1,09 & 1,68 & 1,95 & \\
\hline Índice de Pielou (E) & & 0,68 & 0,81 & 0,81 & \\
\hline
\end{tabular}

As vegetações arbustiva e arbórea que se configuram como suporte das bromélias nas áreas estudadas apresentam diferentes características, conforme as espécies que as constituem e o estádio sucessional em que se encontram. Na capoeirinha, onde 11 espécies arbustivas foram amostradas, não houve registro de bromélias. Na capoeira, Miconia ligustroides apresentou maior densidade relativa e maior número de espécies de bromélias dentre as sete espécies de árvores amostradas. Dentre as 21 espécies de árvores do capoeirão, Miconia cinnamomifolia e Piptocarpha tomentosa ocorreram com as maiores densidades e com o maior número de espécies de bromélias. $\mathrm{Na}$ floresta secundária, que apresentou 34 espécies de árvores, os forófitos com maiores densidades relativas, Maytenus sp. e Guapira opposita, também foram aqueles com maior registro de espécies de bromélias.

A análise de componentes principais para o estádio capoeira apresentou quatro autovalores superiores a um, acumulando $81,44 \%$ da variância total (Tabela 2). A análise fatorial mostrou que o DAP é uma importante variável para caracterizar a ocorrência de bromélias epifíticas nesse estádio, pois dominou o fator 1. A relação entre o número de bromélias e o eixo do fator 1 (DAP) mostrou-se inversa (Figura 1). O segundo fator foi caracterizado pelas variáveis copas fraca e média (Tabela 2), com as quais o número de bromélias apresentou relação direta.

Acumulando 82,26\% da variância total, cinco autovalores maiores que um, no capoeirão, foram obtidos pela análise de componentes principais (Tabela 3). Segundo a análise fatorial, o primeiro fator foi caracterizado pelas variáveis que descrevem as dimensões dos forófitos (DAP e altura), e o segundo fator pelas variáveis copa exuberante e copa média (Tabela 3). Com os dois eixos, a relação do número de espécies de bromélias foi direta (Figura 2).

$\mathrm{Na}$ floresta secundária, cinco autovalores maiores que um acumularam 85,70\% da variância total. O primeiro fator estabelecido pela análise fatorial também foi dominado pelas variáveis DAP e 
altura, enquanto ritidoma rugoso e ritidoma áspero dominaram o segundo fator. Assim como no estádio capoeirão, o número de espécies de bromélias apresentou relação direta com os dois eixos (Figura 3).

Tabela 2. Correlação das variáveis com os fatores 1, 2, 3 e 4, calculadas pela análise fatorial, no estádio capoeira, Ilha de Santa Catarina.

Table 2. Correlation of variables to factors 1,2, $3 \mathrm{e} \mathrm{4}$, calculated by factorial analysis, at capoeira stage, Santa Catarina Island.

\begin{tabular}{lcccc}
\hline \multirow{2}{*}{ Variáveis } & \multicolumn{4}{c}{ Fatores } \\
\cline { 2 - 5 } & $\mathbf{1}$ & $\mathbf{2}$ & $\mathbf{3}$ & $\mathbf{4}$ \\
\hline DAP & 0,91645 & $-0,20530$ & 0,04165 & 0,0370 \\
Altura & 0,24962 & $-0,03043$ & $-0,07086$ & 0,8124 \\
PIM & $-0,41918$ & $-0,07084$ & 0,00241 & 0,7807 \\
Copa fraca & $-0,01567$ & 0,94188 & $-0,31422$ & $-0,0398$ \\
Copa média & 0,03196 & $-0,84426$ & $-0,52687$ & 0,0740 \\
Copa exuberante & $-0,02075$ & $-0,04702$ & 0,98753 & $-0,0441$ \\
\% total da variância & 24,41 & 22,57 & 18,86 & 15,60 \\
\% acumulada da variância & 24,41 & 46,97 & 65,83 & 81,44 \\
\hline
\end{tabular}

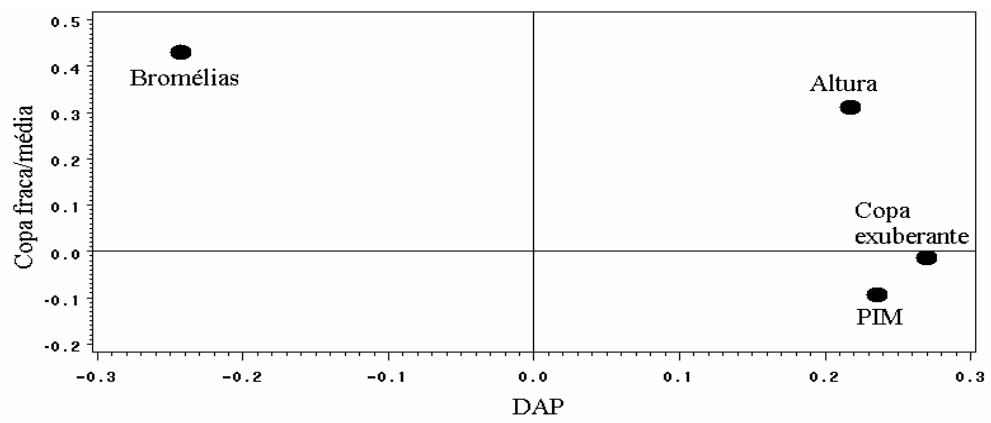

Figura 1. Relação da variável número de espécies de bromélias com os eixos definidos pela análise fatorial, no estádio capoeira, Ilha de Santa Catarina.

Figure 1. Relation of the number of bromeliads species variable with the axes defined by factorial analysis, in the capoeira stage, Santa Catarina Island.

Tabela 3. Correlação das variáveis com os fatores 1, 2, 3, 4 e 5, calculadas pela análise fatorial, no estádio capoeirão, Ilha de Santa Catarina.

Table 3. Correlation of variables to factors $1,2,3$, 4 e 5 calculated by factorial analysis, at capoeirão stage, Santa Catarina Island.

\begin{tabular}{lccccc}
\hline \multirow{2}{*}{ Variáveis } & \multicolumn{5}{c}{ Fatores } \\
\cline { 2 - 6 } & $\mathbf{1}$ & $\mathbf{2}$ & $\mathbf{3}$ & $\mathbf{4}$ & $\mathbf{5}$ \\
\hline DAP & 0,9364 & 0,0899 & $-0,0813$ & $-0,0653$ & 0,1076 \\
Altura & 0,7365 & 0,0025 & 0,0632 & $-0,0389$ & 0,1065 \\
PIM & $-0,0270$ & $-0,0675$ & 0,1460 & 0,0806 & 0,0159 \\
Copa fraca & 0,0116 & 0,0786 & $-0,0900$ & 0,1261 & 0,9196 \\
Copa média & $-0,0932$ & $-0,9062$ & 0,0396 & $-0,0222$ & $-0,4047$ \\
Copa exuberante & 0,0906 & 0,9086 & 0,0323 & $-0,0810$ & $-0,3299$ \\
Ritidoma liso & $-0,0840$ & $-0,0524$ & $-0,1138$ & 0,9742 & $-0,0009$ \\
Ritidoma áspero & $-0,0570$ & 0,0356 & $-0,7717$ & $-0,5995$ & 0,0589 \\
Ritidoma rugoso & 0,1414 & 0,0133 & 0,9229 & $-0,3124$ & $-0,0611$ \\
Ritidoma descamante & 0,2222 & $-0,1190$ & 0,0129 & $-0,3700$ & 0,6535 \\
\% total da variância & 24,21 & 18,72 & 14,98 & 14,23 & 10,12 \\
\% acumulada da variância & 24,21 & 42,93 & 57,91 & 72,14 & 82,26 \\
\hline
\end{tabular}




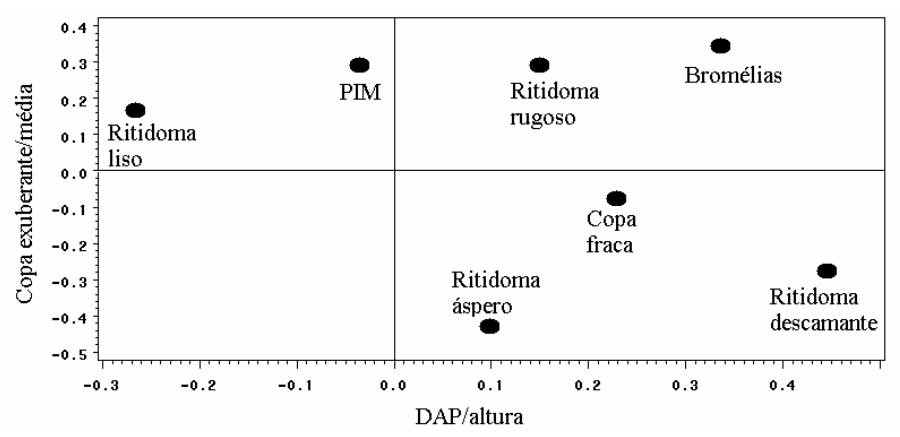

Figura 2. Relação da variável número de espécies de bromélias com os eixos definidos pela análise fatorial, no estádio capoeirão, Ilha de Santa Catarina.

Figure 2. Relation of the number of bromeliads species variable with the axes defined by factorial analysis, in the capoeirão stage, Santa Catarina Island.

Tabela 4. Correlação das variáveis com os fatores 1, 2, 3, 4 e 5, calculadas pela análise fatorial, no estádio floresta secundária, Ilha de Santa Catarina.

Table 4. Correlation of variables to factors $1,2,3,4$ e 5 calculated by factorial analysis, at secondary forest stage, Santa Catarina Island.

\begin{tabular}{lccccc}
\hline \multirow{2}{*}{ Variáveis } & \multicolumn{5}{c}{ Fatores } \\
\cline { 2 - 6 } & $\mathbf{1}$ & $\mathbf{2}$ & $\mathbf{3}$ & $\mathbf{4}$ & \multicolumn{1}{c}{$\mathbf{5}$} \\
\hline DAP & 0,7811 & $-0,1426$ & 0,2642 & 0,0603 & $-0,2673$ \\
Altura & 0,5450 & $-0,1014$ & 0,7820 & 0,0002 & $-0,0268$ \\
PIM & $-0,1159$ & 0,0954 & 0,9158 & $-0,0567$ & 0,1887 \\
Ritidoma liso & 0,0336 & $-0,0907$ & $-0,0919$ & 0,0647 & $-0,0392$ \\
Ritidoma áspero & 0,0186 & $-0,7608$ & 0,0346 & $-0,0446$ & 0,0640 \\
Ritidoma rugoso & $-0,0536$ & 0,9771 & 0,0464 & $-0,0089$ & $-0,0380$ \\
Copa fraca & $-0,0846$ & $-0,0632$ & 0,1451 & $-0,1306$ & 0,9618 \\
Copa média & 0,0661 & 0,0314 & $-0,0556$ & $-0,7554$ & $-0,6470$ \\
Copa exuberante & 0,0101 & 0,0273 & $-0,0810$ & 0,9621 & $-0,2296$ \\
\% total da variância & 22,11 & 19,59 & 16,19 & 15,83 & 11,98 \\
\% acumulada da variância & 22,11 & 41,70 & 57,89 & 73,72 & 85,70 \\
\hline
\end{tabular}

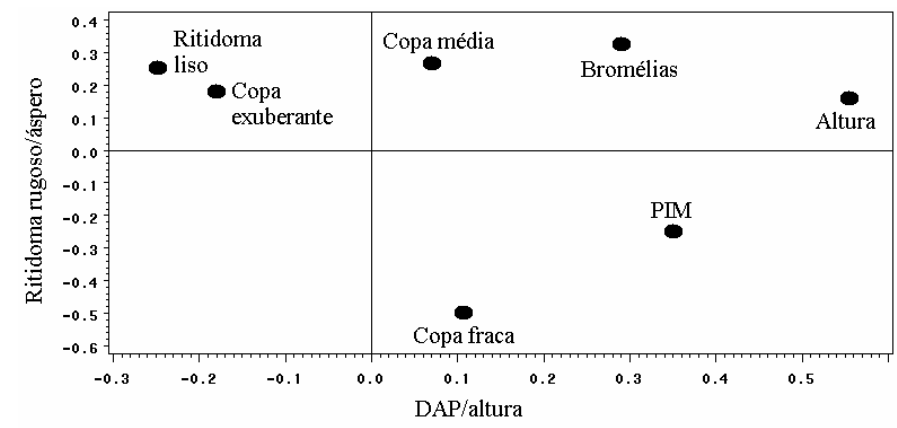

Figura 3. Relação da variável número de espécies de bromélias com os eixos definidos pela análise fatorial, no estádio floresta secundária, Ilha de Santa Catarina.

Figure 3. Relation of the number of bromeliads species variable with the axes defined by factorial analysis, in the floresta secundária stage, Santa Catarina Island. 


\section{DISCUSSÃO}

Os números de espécies obtidos neste estudo podem ser considerados semelhantes aos de pesquisas realizadas em outras áreas da Floresta Ombrófila Densa (Tabela 5). Entre os trabalhos comparados, algumas áreas com grande diversidade de espécies são também áreas com altas médias anuais de precipitação, como Juréia, Ilha Grande, Salto Morato, Ilha do Mel e Ilhota, pois uma das condições limitantes ao epifitismo é a diminuição da distribuição pluviométrica (GENTRY; DODSON, 1987a; WAECHTER, 1992).

Tabela 5. Forma de vida, riqueza específica (R), índice de diversidade (H') e eqüidade (E) de diversos trabalhos realizados na Floresta Ombrófila Densa, Brasil (índice de Shannon e de Pielou calculados para bromeliáceas). $\mathrm{P}=$ precipitação média anual; $\mathrm{FV}=$ forma de vida $(\mathrm{E}=$ epifítica, $G=$ geral).

Table 5. Life form, richness (R), diversity (H') and equitability (E) indexes of different studies carried out in Atlantic Rain Forest, Brazil (Shannon and Pielou indexes calculated for bromeliads). $\mathrm{P}=$ mean annual precipitation; $\mathrm{FV}=$ life form $(\mathrm{E}=$ epiphytic, $\mathrm{G}=$ general $)$.

\begin{tabular}{|c|c|c|c|c|c|c|c|}
\hline Autor & Local & $\mathbf{P}(\mathbf{m m})$ & Vegetação & FV & $\mathbf{R}$ & H' & $\mathbf{E}$ \\
\hline \multirow[t]{4}{*}{ Presente estudo } & Florianópolis - SC & 1.527 & Capoeirinha & $\mathrm{E}$ & 0 & - & - \\
\hline & & & Capoeira & & 5 & 1,09 & 0,68 \\
\hline & & & Capoeirão & & 8 & 1,68 & 0,81 \\
\hline & & & Floresta secundária & & 11 & 1,95 & 0,81 \\
\hline Bonnet (2006) & $\begin{array}{l}\text { Rio Iguaçu (vários } \\
\text { municípios) - PR }\end{array}$ & 1.600 & Planície fluvial & $\mathrm{E}$ & 14 & - & - \\
\hline \multirow{5}{*}{$\begin{array}{l}\text { Hoeltgebaum } \\
(2003)\end{array}$} & Ilhota - SC & 1.900 & Capoeirinha & $\mathrm{E}$ & 0 & - & - \\
\hline & & & Capoeira & & $*$ & - & - \\
\hline & & & Capoeirão & & 11 & 1,98 & 0,83 \\
\hline & & & Floresta secundária & & 19 & 2,50 & 0,85 \\
\hline & & & Floresta primária & & 24 & 2,69 & 0,85 \\
\hline \multirow[t]{4}{*}{ Rogalski (2002) } & Florianópolis - SC & 1.527 & Fundo de vale & $\mathrm{E}$ & 15 & 2,50 & 0,92 \\
\hline & & & Meia encosta & & 13 & 2,25 & 0,88 \\
\hline & & & Topo morro sem aflor. roch. & & 13 & 1,95 & 0,76 \\
\hline & & & Topo morro com aflor. roch. & & 8 & 1,76 & 0,85 \\
\hline $\begin{array}{l}\text { Kersten; Silva } \\
(2001)\end{array}$ & Paranaguá - PR & 1.960 & Restinga & $\mathrm{E}$ & 16 & - & - \\
\hline Matos (2000) & $\begin{array}{l}\text { Santo Amaro da } \\
\text { Imperatriz - SC }\end{array}$ & 1.600 & Vegetação secundária & G & 19 & 2,39 & 0,81 \\
\hline Gatti (2000) & Guaraqueçaba - PR & 2.000 & Floresta primária & $\mathrm{E}$ & 31 & - & - \\
\hline Breier (1999) & Viamão - RS & 1.309 & Restinga & $\mathrm{E}$ & 12 & - & - \\
\hline \multirow{3}{*}{$\begin{array}{l}\text { Almeida et al. } \\
\text { (1998) }\end{array}$} & Ilha Grande - RJ & 2.240 & Área antrópica & $\mathrm{G}$ & 8 & 0,55 & 0,31 \\
\hline & & & Vegetação secundária & & 8 & 0,98 & 0,47 \\
\hline & & & Vegetação primária & & 17 & 1,61 & 0,59 \\
\hline \multirow{4}{*}{$\begin{array}{l}\text { Fischer; Araújo } \\
\text { (1995) }\end{array}$} & Estação Ecológica de & 4.200 & Floresta ripária & $\mathrm{G}$ & 15 & - & - \\
\hline & Juréia (vários & & Floresta densa & & 10 & & \\
\hline & municípios) - SP & & Restinga & & 13 & & \\
\hline & & & Costão rochoso & & 6 & & \\
\hline Waechter (1998) & Osório - RS & 1.325 & Restinga & $\mathrm{E}$ & 13 & - & - \\
\hline \multirow[t]{2}{*}{ Waechter (1992) } & Torres/Taim - RS & 1.277 & Floresta turfosa & $\mathrm{E}$ & 22 & - & - \\
\hline & & & Floresta brejosa & & 5 & - & - \\
\hline
\end{tabular}

* foram registradas apenas plântulas de bromélias.

Do mesmo modo, a importância da alta umidade dos microclimas de formações específicas destaca-se no estudo de Waechter (1992), de Fischer e Araújo (1995), de Rogalski (2002) e de Bonnet (2006). Para a flora epifítica das florestas fluviais (FISCHER; ARAÚJO, 1995; BONNET, 2006), a presença do rio estabelece uma fonte constante de umidade. Sua proximidade possibilita que mesmo espécies normalmente habitantes de ambientes sombreados possam tolerar maior intensidade luminosa se esses locais tiverem umidade suficiente, como ocorre nas áreas próximas de rios (BENZING, 1995). Sob 
condições turfosas (WAECHTER, 1992), por sua vez, a umidade atmosférica é fornecida constantemente pelos solos orgânicos (Organossolos), que apresentam alta porosidade preenchida por água. Do mesmo modo, o fundo de vale (ROGALSKI, 2002) é local de convergência hídrica, favorecendo a alta umidade atmosférica.

O gradiente latitudinal é outro fator importante que deve ser considerado quando os números de espécies são comparados, pois provoca diminuição na riqueza no sentido sudeste-sul do Brasil. Mais especificamente em Santa Catarina, a diminuição de espécies de bromélias no sentido norte-sul é associada à interferência das serras de Tijucas e do Tabuleiro (REITZ, 1983). Na Planície Costeira do Rio Grande do Sul, também é constatada diminuição, no sentido norte-sul, da riqueza florística de epífitas (WAECHTER, 1992).

Nos estudos realizados em áreas protegidas, como os de Salto Morato (PR) e Ilhota (SC), onde a riqueza de espécies de bromélias é elevada, o estado de conservação da vegetação é determinante para a ocorrência de bromélias epifíticas.

No presente estudo, as bromélias ocorreram sobre indivíduos arbustivos e arbóreos a partir da capoeira, estabelecendo um padrão de colonização definido tanto pela presença de plântulas como de plantas adultas, padrão esse intensificado nos estádios seguintes. Houve trocas e substituições de espécies e gêneros nos sucessivos estádios de regeneração da floresta, com aumento do número de espécies (Tabela 1), da proporção em que estas participam da comunidade (Tabela 2), da similaridade, como também dos valores de importância das espécies (BONNET; QUEIROZ, 2006).

Entre o capoeirão e a floresta secundária não ocorreu nem perda nem substituição de espécies (amplas A - Tabela 3), apenas três novas espécies foram acrescentadas nesta última (restritas B). Essa similaridade é confirmada pelo índice de Jaccard e pode indicar que as condições ambientais próprias para a colonização dos forófitos pela maioria das espécies de bromélias epifíticas identificadas já podem ser encontradas no capoeirão. O menor índice de similaridade obtido entre a capoeira e a floresta secundária reflete maiores diferenças entre estes dois estádios, o que se deve, provavelmente, às condições microclimáticas dominantes, além da qualidade e quantidade de substrato disponível para desenvolvimento dos indivíduos. Almeida et al. (1998) também detectaram aumento na riqueza, diversidade e eqüitabilidade das espécies no sentido das áreas mais degradadas àquelas com menor degradação.

A ausência de bromélias na capoeirinha está provavelmente relacionada ao pouco tempo em que o substrato está disponível para colonização, mesmo estando a vegetação inserida em um mosaico de florestas em vários estádios sucessionais e, provavelmente, recebendo sementes das bromélias que se reproduzem nas proximidades. No entanto, o pequeno porte e rápido crescimento dos forófitos deste estádio não favorecem o registro de bromélias, pois, segundo Yeaton e Gladstone (1982), o tempo em que o substrato está disponível para colonização é o fator fundamental para colonização, mais importante que o tamanho da área (representando diversidade de hábitats) e que a distância de propagação dos diásporos. Nesse sentido, o tempo em que o substrato está disponível para colonização na floresta pode ser verificado, primeiramente, através da altura e do diâmetro dos forófitos.

Na capoeira, a relação inversa do número de espécies de bromélias com a variável que descreve a dimensão dos forófitos (DAP), constatada pela análise fatorial, pode ser justificada pela baixa variabilidade estrutural dessa formação, onde existe alta dominância de arvoretas de Miconia ligustroides. Essa espécie apresenta, caracteristicamente, grande número de perfilhos, fator que influencia muito mais no diâmetro final dos forófitos do que, propriamente, a idade dos indivíduos arbóreos. Sendo assim, é provável que, nesse estádio, as características dos forófitos sejam menos importantes do que as condições microclimáticas para a ocorrência de alto número de bromeliáceas epifíticas. A luminosidade incidente neste ambiente pode ser considerada alta, pois os forófitos crescem de modo esparso, condicionando maiores temperaturas e menor porcentagem de umidade relativa.

As condições microclimáticas encontradas no estádio capoeira vêm ao encontro das características ecológicas das espécies heliófilas e atmosféricas (REITZ, 1983) registradas com os maiores valores de importância neste estádio (BONNET; QUEIROZ, 2006): Tillandsia mallemontii e T. stricta, além de $T$. geminiflora, que ocorreu com menor freqüência. Elas possuem alta densidade de tricomas ao longo das folhas para absorção de nutrientes e umidade da atmosfera, e para conferir resistência à supressão hídrica e intensa radiação (BENZING, 1976; HIETZ; HIETZ-SEIFERT, 1995), tornando-as adaptadas a este ambiente. $\mathrm{O}$ fato de as espécies com maiores valores de importância serem 
caracterizadas como heliófilas também está de acordo com a relação direta encontrada entre o número de espécies de bromélias e o segundo eixo, dominado pelas variáveis copa fraca e média, pois nessas situações a luminosidade incidente no ritidoma dos forófitos é maior do que quando a copa é caracterizada como exuberante.

No estádio de capoeirão, as espécies de bromélias apresentaram forte relação com o DAP e altura total dos forófitos, concordando com Hietz e Hietz-Seifert (1995), Yeaton e Gladstone (1982) e Shaw (2004), que afirmam que forófitos com maiores dimensões oferecem maior área para fixação das plântulas, maior possibilidade de formação de microclimas diversos, como também devem estar a um período maior de tempo crescendo na floresta, resultando numa forte relação dos grandes indivíduos arbóreos com riqueza de bromélias. Os forófitos com maiores dimensões neste estádio foram $M$. cinnamomifolia e $P$. tomentosa, que também apresentaram o maior número de espécies de bromélias. A despeito das diferenças quanto ao ritidoma, seus indivíduos eram comumente vigorosos e suas copas enquadradas como exuberantes ou médias, o que foi detectado pela análise fatorial na relação direta da riqueza de bromélias com o eixo dominado por essas variáveis (Figura 2).

$\mathrm{Na}$ floresta secundária, apesar da maior diversidade de arbóreas que, em conjunto, oferecem uma grande variedade de substratos e formas, a riqueza de bromélias epifíticas também se mostrou diretamente relacionada às dimensões dos forófitos, assim como no estádio capoeirão. Essa relação remete novamente ao tempo de exposição, à quantidade de substrato e à formação de micro-hábitats nos forófitos como fatores preponderantes, dentre os analisados, ao epifitismo. Ao mesmo tempo, a relação direta das bromélias com as variáveis ritidoma áspero e rugoso, que dominaram o segundo eixo (Figura 3), indica que o ritidoma liso é inadequado para a colonização por bromélias epifiticas. Do mesmo modo, é provável que forófitos com ritidoma descamante também não sejam adequados para fixação das plântulas ou sobrevivência das bromélias maiores, como as bromélias-tanque. Por outro lado, nas florestas da planície do rio Iguaçu (BONNET et al., 2006), mirtáceas com ritidoma descamante se mostraram importantes suportes de bromélias. Outros parâmetros de qualidade do ritidoma, como presença de toxinas, porosidade e quantidade de húmus acumulado, devem ter sua importância diminuída para plantas que geralmente apresentam raízes sem função de absorção, mas apenas de fixação, como é o caso de bromélias.

A relação direta das bromélias com o diâmetro dos forófitos evidencia a semelhança entre os estádios capoeirão e floresta secundária, semelhança esta também detectada pelo alto índice de Jaccard.

As variáveis que definem a abundância das copas (copa fraca, média e exuberante) e que deveriam avaliar a influência da luminosidade incidente, parecem não ser significativamente importantes na floresta secundária, principalmente quando se considera a influência de clareiras e de relevos mais declivosos, que propiciam maior luminosidade incidente nas florestas.

Dentre as características forofíticas analisadas, as dimensões dos forófitos, que traduzem, em uma primeira análise, o tempo em que o substrato está disponível para colonização, se mostraram elementos fundamentais na definição da riqueza de bromeliáceas epifíticas nos estádios mais avançados de sucessão. Esse resultado está de acordo com aqueles obtidos no Paraná (GATTI, 2000; BONNET, 2006; BONNET et al., 2006), em Santa Catarina (HOELTGEBAUM, 2003), no Rio Grande do Sul (BREIER, 1999) e no Rio de Janeiro (FONTOURA et al., 1997). Nos estádios iniciais de sucessão, como a capoeira, as variáveis microclimáticas são mais importantes que o ritidoma, copa ou tamanho de forófito, favorecendo espécies de bromélias que suportam condições de alta luminosidade e baixa umidade relativa em detrimento daquelas que necessitam acumular água em suas rosetas e não apresentam estratégias adaptativas para a supressão hídrica e intensa radiação.

É importante ressaltar que o registro do maior número de espécies de bromélias exatamente nas espécies forofíticas que apresentaram as maiores densidades em cada estádio sucessional sugere que não houve preferências das bromélias por forófito específico. O consenso na literatura disponível é de que as epífitas exigem condições que muitos forófitos podem proporcionar, dependendo principalmente da idade ou das condições ambientais, particularmente umidade e luminosidade, ou outras condições, como a disponibilidade de colonizadores. Segundo Benzing (1995), estudos localizados podem eventualmente demonstrar preferências de epífitas por certos tipos de forófitos que não seriam confirmadas se os mesmos fossem realizados em áreas maiores. Nesse sentido, a baixa ocorrência das bromélias na capoeira e no capoeirão e o aumento da diversidade de espécies de forófitos na floresta secundária também dificultam o estudo da relação de especificidade forófito-bromélia, pois várias árvores ocorreram apenas 
uma vez no levantamento. Sendo assim, essa relação não foi testada. No entanto, nenhuma das espécies de bromélia que ocorreu mais de uma vez mostrou exclusividade na ocupação de determinada espécie forofítica, o que está de acordo com os resultados da análise fatorial, que evidenciaram correlações das bromélias com as dimensões dos indivíduos arbóreos.

\section{AGRADECIMENTOS}

Agradecemos à CAPES, pela concessão de bolsa à primeira autora deste artigo; aos pesquisadores Gustavo Ribas Curcio e Renato Dedecek (Embrapa Florestas), pelas sugestões e correções feitas no manuscrito; ao biólogo Werner W. Bonnet, pela base técnica de escalada em árvores; e aos revisores, pelas sugestões.

\section{REFERÊNCIAS}

AGUiAR, L. W.; CITADINI-ZANETTE, V.; MARTAU, L.; BACKES, A. Composição florística de epífitos vasculares numa área localizada nos Municípios de Montenegro e Triunfo, Rio Grande do Sul, Brasil. Iheringia, Série Botânica, Porto Alegre, v. 28, p. 55-93, 1981.

ALMEIDA, D. R.; CARVALHO, L. C.; ROCHA, C. F. D. As bromeliáceas da Mata Atlântica da Ilha Grande, RJ: composição e diversidade de espécies em três ambientes diferentes. Bromélia, Rio de Janeiro,v. 5, p. 55-65, 1998.

BENZING, D. H. Bromeliad trichomes: structure, function, and ecological significance. Selbyana, Sarasota, v. 1, p. 330-348, 1976.

BENZING, D. H. Vascular epiphytes in forest canopies. In: M.D.LOWMAN; N.M.NADKARNI. Forest Canopies. California: Academic, 1995, p. 225-254.

BONNET, A. Caracterização fitossociológica das bromeliáceas epifíticas e suas relações com os fatores geomorfológicos e pedológicos na planície do rio Iguaçu, Paraná, Brasil. 292f. Tese (Doutorado em Conservação da Natureza) - Setor de Ciências Agrárias, Universidade Federal do Paraná, Curitiba, 2006.

BONNET, A.; QUEIROZ, M. H. Estratificação vertical de bromélias epifíticas em diferentes estádios sucessionais da Floresta Ombrófila Densa, Ilha de Santa Catarina, Santa Catarina, Brasil. Revista Brasileira de Botânica, São Paulo, v. 29, n. 2, p. 217-228, 2006.

BONNET, A., RODERJAN, C. V.; CURCIO, G. R.; BARDDAL, M. L.; LAVORANTI, O. J. Vegetação arbórea e bromeliáceas epifíticas em duas unidades geomórficas da planície do rio Iguaçu, Paraná, Brasil. Floresta, Curitiba, 2006. No prelo.

BREIER, T. B. Florística e ecologia de epífitos vasculares em uma Floresta Costeira do Sul do Brasil. 75f. Dissertação (Mestrado em Botânica), Universidade Federal do Rio Grande do Sul, Porto Alegre, 1999.

DISLICH, R.; MANTOVANI, W. Flora de epífitas vasculares da Reserva da Cidade Universitária "Armando de Salles Oliveira" (São Paulo, Brasil). Boletim de Botânica da Universidade de São Paulo, v. 17, p. 61-83, 1998.

DITTRICH, V. A. O., KOZERA, C.; SILVA, S. M. Levantamento florístico dos epífitos vasculares do Parque do Barigui, Curitiba, Paraná, Brasil. Iheringia. Série Botânica, Porto Alegre, v. 52, p. 11-21, 1999.

DRAPER, N.; SMITH, H. Applied Regression Analysis. Hoboken: J. Wiley and Sons, 1981.

FISCHER, A. E.; ARAÚJO, A. C. Spatial organization of a bromeliad community in the Atlantic rainforest, south-eastern Brazil. Journal of Tropical Ecology, Cambridge, v. 11, p. 559-567, 1995. 
FONTOURA, T.; SYLVESTRE, L. S.; VAZ, A. M. S.; VIEIRA, C. M. Epífitas vasculares, hemiepífitas e hemiparasitas da Reserva Ecológica de Macaé de Cima. In: LIMA, H. C.; GUEDES-BRUNI, R. R. Serra de Macaé de Cima: diversidade florística e conservação da Mata Atlântica. Rio de Janeiro: Editora do Jardim Botânico do Rio de Janeiro, 1997, p.89-101.

GABRIEL, K. R. Le biplot - outil d'exploration de données multidimensionelles. Journal de la Societe Francaise de Statistique, [Paris], v. 143, p. 5-55, 2002.

GARCIA-FRANCO, J. G; RICO-GRAY, V. Experiments on seed dispersal and deposition patterns of epiphytes - the case of Tillandsia deppeana Steudel (Bromeliaceae). Phytologia, Huntsville, v. 65, p. 73$78,1988$.

GATTI, A. L. S. O componente epifítico vascular na Reserva Natural de Salto Morato, Guaraqueçaba - PR. 93f. Dissertação (Mestrado em Botânica) - Setor de Ciências Biológicas, Universidade Federal do Paraná, Curitiba, 2000.

GENTRY, A. H.; DODSON, C. H. Diversity and Biogeography of Neotropical Vascular Epiphytes. Annals of the Missouri Botanical Garden, Saint Louis, Mo., v. 74, p. 205-233, 1987a.

GENTRY, A. H.; DODSON, C. Contribution of Nontrees to species Richness of a Tropical Rain Forest. Biotropica, Washington, DC, v. 19, p. 149-156, 1987 b.

HIETZ, P.; HIETZ-SEIFERT, U. Composition and ecology of vascular epiphyte communities along na altitudinal gradient in central Veracruz, México. Journal of Vegetation Science, Knivsta, v. 6, p. 487498, 1995.

HOELTGEBAUM, M. P. Composição florística e distribuição espacial de bromélias epifíticas em diferentes estádios sucessionais da Floresta Ombófila Densa, Parque Botânico Morro Baú, Ilhota, SC. 138f. Dissertação (Mestrado em Biologia Vegetal) - Universidade Federal de Santa Catarina, Florianópolis, 2003.

INDEX KEWENSIS 2.0. Oxford: Oxford University Press, 1997. 1 CD-ROM.

IPUF. Estudos ambientais da grande Florianópolis. Florianópolis: Instituto Brasileiro de Geografia e Estatística/Instituto de Planejamento Urbano de Florianópolis, 1997.

JOHNSON, R. A.; WICHERN, D. W. Applied multivariate statistical analysis. New Jersey: Prentice Hall, 1998.

KAISER, H. F. The varimax criterion for analytic rotation in factor analysis. Psychometrika, Williamsburg, Va., v. 23, p. 187-200, 1958.

KERSTEN, R. A.; SILVA, S. M. Composição florística e estrutura do componente epifítico vascular em floresta da planície litorânea na Ilha do Mel, Paraná, Brasil. Revista Brasileira de Botânica, São Paulo, v. 24, p. 213-226, 2001.

KERSTEN, R. A.; SILVA, S. M. Florística e estrutura do componente epifítico vascular em Floresta ombrófila mista aluvial do rio Barigüi, Paraná, Brasil. Revista Brasileira Botânica, São Paulo, v. 25, p. 259-267, 2002.

KLEIN, R. M. Ecologia da flora e vegetação do vale do Itajaí. Sellowia, Itajaí, v. 31-32, p. 9-389, 1980.

KRAEMER, H. C. Biserial Correlation. Encyclopaedia of Statistical Sciences, v. 1, p.276-279, 1982.

LEME, E. M. C. Nidularium - Bromélias da Mata Atlântica. Rio de Janeiro:Sextante Artes. 2000.

LUGO, A. E.; SCATENA, F. N. Epiphytes and climate change research in the Caribbean: a proposal. Selbyana, Sarasota, v. 13, p. 123-130, 1992.

MAGURRAN, A. E. Ecological diversity and its measurement. New Jersey: Princeton University Press, 1988. 
MARTIN, C. E. Physiological Ecology of the Bromeliaceae. Botanical Review, Bronx, v .60, p. 1-82. 1994.

MUELLER-DOMBOIS, D.; ELLENBERG, H. Aims and methods of vegetation ecology. New York: J. Wiley e Sons, 1974.

NADKARNI, N. M. Epiphyte biomass and nutrient capital of a neotropical elfin forest. Biotropica, Washington, DC, v. 16, p. 249-256, 1984.

NIEDER, J.; ENGWALD, S.; BARTHLOTT, W. Spatial distribution of vascular epiphytes (including Hemiepiphytes) in a Lowland Amazonian Rain Forest (Surumoni Crane Plot) of Southern Venezuela. Biotropica, v.32, p.385-396, 2000.

PINTO, A. C. R.; DEMATTÊ, M. E. S. P.; PAVANI, M. C. M. D. Composição florística de epífitas (Magnoliophyta) em fragmento de floresta no município de Jaboticabal, SP, Brasil. Científica: Revista de Agronomia, São Paulo, v. 23, p. 283-289, 1995.

PORTO FILHO, E. Sedimentologia e algumas considerações sobre a bioquímica dos sedimentos do fundo da Lagoa da Conceição, Ilha de Santa Catarina. Dissertação (Mestrado em Geografia) Universidade Federal de Santa Catarina, Florianópolis, 1993.

QUEIROZ, M. H. Approche phytoécologique et dynamique des formations végétales secondaires développées après abandon des activités agricoles, dans le domaine de la forêt ombrophile dense (Forêt Atlantique) à Santa Catarina - Brésil. Tese (Doutorado) - École Nationale du Génie Rural, des Eaux et des Forêts, Nancy,1994.

REITZ, R. Bromeliáceas e a malária - bromélia endêmica. In: REITZ, R. (Ed.). Flora Ilustrada Catarinense. Itajaí: Herbário Barbosa Rodrigues, 1983. 1 CD-ROM.

ROCHA, C. F. D.; COGLIATTI-CARVALHO, L.; NUNES-FREITAS, A.F.; ROCHA-PESSOA, T.C.; DIAS, A. S.; ARIANI, C. V.; MORGADO, L. N. Conservando uma larga proporção da diversidade biológica através da conservação de Bromeliaceae. Vidalia, Viçosa, M.G., v. 2, p. 52-68, 2004.

ROGALSKI, J. M. Distribuição espacial de bromélias e aráceas epifíticas em diferentes situações topográficas de Floresta Ombrófila Densa, Ilha de Santa Catarina/SC. 126f. Dissertação (Mestrado em Biologia Vegetal) - Universidade Federal de Santa Catarina Florianópolis, 2002.

ROGALSKI, J. M.; ZANIN, E. M. Composição florística de epífitos vasculares no estreito de Augusto César, floresta Estacional Decidual do Rio Uruguai, RS, Brasil. Revista Brasileira de Botânica, São Paulo, v. 26, p. 551-556, 2003.

SHAW, D. C. Vertical organization of canopy biota. In: LOWMAN, M.D.; RINKER, H. B.. Forest Canopies. London: Elsevier Academic, 2004. p.73-101.

WAECHTER, J. L. O epifitismo vascular na planície costeira do Rio Grande do Sul. Tese (Doutorado em Ecologia e Recursos Naturais), Universidade Federal de São Carlos, São Carlos,1992.

YEATON, R. I.; GLADSTONE, D. E. The pattern of colonization of epiphytes on Calabash Trees (Crescentia alata HBK.) in Guanacaste Province, Costa Rica. Biotropica, Washington, DC,v. 14, p. 137$140,1982$. 